\title{
The latest in dementia prevention: A review of the promising role of aerobic exercise
}

\author{
Kenta Shigemori ${ }^{1}$ \\ 1) Kansai University of Welfare Sciences \\ 3-11-1 Asahigaoka, Kashiwara, Osaka, 582-0026, Japan \\ Tel: +81-72-978-0088 e-mail:kenta.shigemori@gmail.com
}

JAHS 7 (2): 37-45, 2016. Submitted Sep. 15, 2016. Accepted Sep. 25, 2016.

\begin{abstract}
:
Aerobic exercise (AE) has been widely acknowledged for improving brain health. In particular, AE has a potent impact on promoting the function of the hippocampus. The potential for $\mathrm{AE}$ to be applied as a therapeutic or adjunctive intervention for a range of human conditions appears increasingly more promising. Augmenting existing treatment approaches using AE-based interventions may promote hippocampal function. Moreover, incorporating non-pharmacological interventions into clinical treatment may have several other benefits for the patient's wellbeing. This review incorporates both animal and human studies to comprehensively detail the association of $\mathrm{AE}$ with cognitive enhancements.
\end{abstract}

Key words: Aerobic exercise (AE), Alzheimer's disease (AD), Brain health

\section{INTRODUCTION}

Alzheimer's disease (AD) is an age-related, progressive, and irreversible neurodegenerative disorder characterized by cognitive and memory impairment. In 2015, a total of 44 million people throughout the world were thought to have $\mathrm{AD}$; it is estimated that this figure will double by 205011. Therefore, there is currently a particular need to develop effective strategies that alleviate cognitive dysfunction. In late years, Aerobic exercise (AE) and lifestyle has been widely acknowledged for improving brain health. In particular, $\mathrm{AE}$ has a potent impact on promoting the function of the hippocampus. There is targeting deficits in the neuroplasticity of crucial areas to cognition like the hippocampus, is a promising approach to remediating cognitive dysfunction. The potential for $\mathrm{AE}$ to be applied as a therapeutic or adjunctive intervention for a range of human conditions appears increasingly more promising. This paper will review the cognitive benefits associated with $\mathrm{AE}$ and focus on aspects of cognition that are particularly dependent hippocampal functioning such as episodic memory formation (Figure1). 


\section{REVIEW}

\section{Lifestyle}

Lifestyle strategies include physical activity, mental challenges, energy restriction, and socialization as preventive factors for $\mathrm{AD}^{2}$. Physical activity, such as aerobic exercise, was associated with a reduction in AD-related deficits in a cohort study ${ }^{3}$. However, a different result was obtained in small cases ${ }^{4}$. Exercise was reported to enhance hippocampal neurogenesis ${ }^{5,6)}$ and learning in aging rodents7). There are three mechanisms proposed to explain the neuroprotective effect of exercise.

(1) The release of neurotrophic factors such as brain-derived neurotrophic factor (BDNF), insulin-like growth factor (IGF-1), nerve growth factor (NGF), and vascular endothelial growth factor (VEGF) ${ }^{8,9)}$ from neurons during synaptic activity, which stimulate neurogenesis and synaptic neural plasticity through the stimulation of the cAMP response element-binding protein (CREB) transcription factor.

(2) The reduction in free radicals in the hippocampus, as well as the increase in superoxide dismutase and endothelial nitric oxide synthase $^{9}$.

(3) Peripheral signals that help to support the demands of active neuronal networks, such as $\mathrm{BDNF}$ release, in addition to energy restriction in the brain ${ }^{10-13)}$.
It has been suggested that mental challenges may protect against cognitive decline and potentially against $\mathrm{AD}^{14)}$. Computer courses and psychoeducation have moderate beneficial effects ${ }^{15)}$. Stimulation by cognitive activities has been associated with an increase in neuronal density, which increases the brain reserve and plasticity2).

The relation between caloric restriction and brain motivation is important; many years ago, humans needed to obtain their food by killing wild animals, which often involved vigorous exercise ${ }^{16)}$. The possible mechanism may be associated with SIRT1, a protein with nicotinamide adenine dinucleotide-dependent deacetylase or adenosine diphosphate-ribosyltransferase activity ${ }^{17}$, because it was reported to increase in p $25 \mathrm{CK}$ mice with characteristics similar to $\mathrm{AD}$. In addition, SIRT1 stimulation by resveratrol protects against neuronal death. SIRT1 levels also increase with NADp in vitro, and SIRT induces an increase in $\alpha$-secretase and decrease in 8-amyloid deposition in primary cultures in a mouse model of $\mathrm{AD}^{18)}$. The relationship between hunger and neuroprotection was demonstrated using ghrelin in a mouse model of $\mathrm{AD}$; the results showed improved cognition in the water maze test and a decrease in amyloid- 8 levels and inflammation ${ }^{19}$.

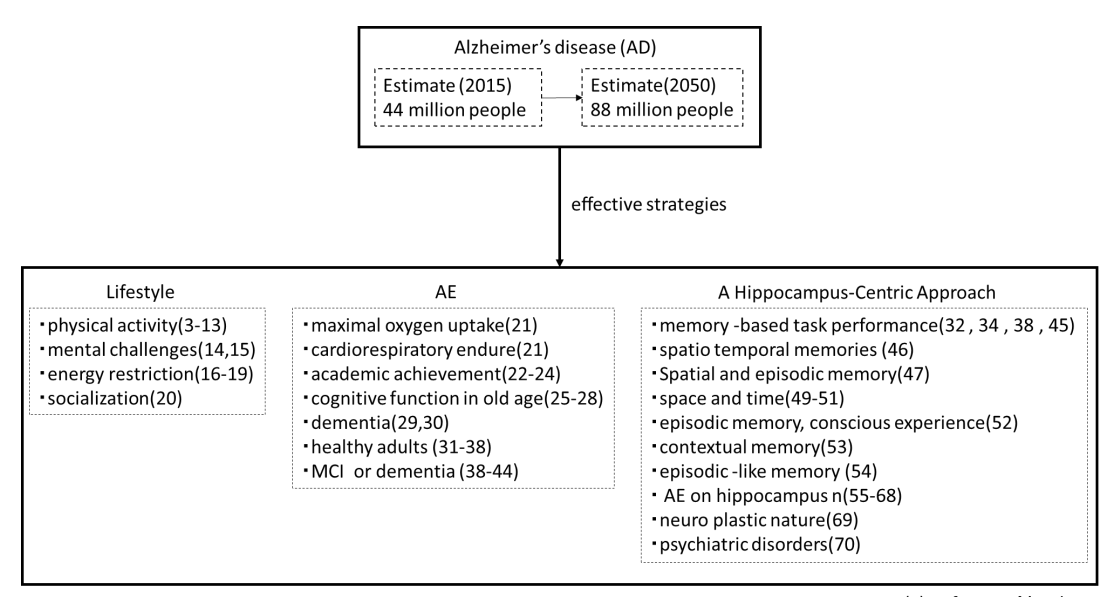

() Reference Number

Figure1. Chart of References Number 
Socialization is important in mental and physical development. A lack of socialization induces loneliness, which has been associated with various diseases such as depression, alcohol abuse, obesity, diabetes, hypertension, $\mathrm{AD}$, and cancer ${ }^{20)}$.

\section{Aerobic Exercise}

The attention paid to how $\mathrm{AE}$ influences cognitive performance has exploded in the past decade. AE generally refers to exercise that improves the efficiency of aerobic energy producing systems by increasing maximal oxygen uptake and cardiorespiratory endurance ${ }^{21)}$ Large-scale epidemiological studies have consistently correlated high levels of aerobic fitness with greater academic achievement and IQ scores $22-24$. However, in addition to greater preservation of cognitive function in old age ${ }^{25-28)}$ and fewer incidences of dementia ${ }^{29)}$, this capacity to promote cognitive performance implies that $\mathrm{AE}$ may have an important clinical relevance in counteracting the cognitive decline associated with aging or dementia $^{30)}$; this implication has catalyzed attempts for systematic investigation. Many randomized controlled trials (RCTs) have recently been conducted using moderate intensity AE interventions (such as $30 \mathrm{~min}$ of Nordic walking) that generally span 3-12 months and are mostly conducted in older adults. Meta-analyses have found $\mathrm{AE}$ interventions to improve cognitive performance across a variety of domains, including attention, executive functioning, processing speed, motor functioning, and memory in healthy young and middle aged adults ${ }^{31-35)}$; notably, this effect is observed predominantly in older age groups ${ }^{31}$, $32,36-38)$ as well as in older individuals with mild cognitive impairments or dementia ${ }^{38-40)}$.

The available evidence strongly suggests that $\mathrm{AE}$ has a positive influence on cognition in individuals of all age groups, particularly in older adults. Some RCTs have stipulated that $\mathrm{AE}$ influences divergent cognitive domains, whereas others have suggested AE had no significant impact on cognition at all $38,40-43$ ). Such inconsistencies may partially be explained by the methodological variation between RCTs, making it difficult to systematically compare their findings in meta-analyses $\left.{ }^{43}, 44\right)$. The exact nature of how $\mathrm{AE}$ affects cognition is not yet clear.

\section{A Hippocampus-Centric Approach}

Several meta-analyses have denoted the tendency for RCTs to report improvements in memory-based task performance following an AE-based intervention $32,34,38,45$ ).

The human hippocampus plays a vital role in the formation of declarative memories, most prominently in the formation of episodic and spatiotemporal memories ${ }^{46}$. Episodic memory refers to the recollection of autobiographical events and is related to spatial memory, which refers to one's environment and spatial orientation. Spatial and episodic memory processes are inherently related given their specific reliance on the hippocampus ${ }^{47)}$ and the fact that episodic memories are encoded in a spatiotemporal context ${ }^{48)}$, making spatial information important in episodic memory formation. Furthermore, the hippocampus, particularly the dentate gyrus (DG), is crucial in selecting and separating similar events in space and time, and hence pattern separation is a main function attributed to the hippocampus ${ }^{49-51)}$. It is important to note that given the requirement of a conscious experience to form an episodic memory, at present episodic memory cannot be directly studied in animals given the lack of behavioral markers for their conscious experience ${ }^{52}$. Contextual memory is a process strongly related to episodic memory that is also highly dependent on the hippocampus and refers to the capacity for an animal to make associations with salient landmark objects and their environmental context ${ }^{53)}$. As there is currently no objective proxy for studying episodic-like memory 
processing in animals ${ }^{54)}$ hippocampal functioning shall be considered here as a function of contextual and spatial memory task performance when referring to animal literature and as a function of episodic and spatial memory task performance when discussing human literature. Some human studies have focused on assessing the influence of AE on hippocampus-dependent cognition and shown in older adults that $\mathrm{AE}$ was associated with improved performance in both episodic $^{55-59)}$ and spatial ${ }^{60-62)}$ memory tasks, as well as in pattern separation tasks in young adults63). Moreover, some studies have demonstrated in preadolescent children and young adults that $\mathrm{AE}$ is selectively associated with improved performance in contextual ${ }^{64-66)}$ and spatial 67,68$)$ memory tasks and not with less hippocampus-dependent tasks such as attention, verbal memory, or item recognition.

We will then discuss both animal and human studies, which indicate that these structural changes may be driven by a cascade of micro-scale neuroplastic mechanisms within the hippocampus stimulated by AE. Despite a limited selection of studies, these findings indicate that $\mathrm{AE}$ may have a positive influence on hippocampus-dependent forms of cognition in healthy human participants, similar to what has been consistently shown in animal models. Pertaining to its highly neuroplastic nature ${ }^{69)}$, the hippocampus is particularly vulnerable to structural and functional deterioration in a wide range of neurological and psychiatric disorders 70 . The aforementioned studies demonstrate that $\mathrm{AE}$ could have a positive influence on hippocampal functioning, but a significantly greater cohort of systematic investigations using human participants will be necessary to outline this relationship on a broader cognitive level. A growing body of evidence is also accumulating to suggest that AE may have a prominent impact on hippocampal structure in humans, as well as in animal models.

\section{LIMITATIONS}

Another issue in the conceptualization of $\mathrm{AE}$-based treatments is the lack of consensus as to what type, intensity, or length of exercise sessions has the strongest impact on the brain. For example, some studies argue that high-intensity exercise is optimal for reducing symptoms in MDD 71), while others have suggested that that a mild ${ }^{72)}$ or a moderate intensity exercise intervention would be optimal73). It is possible that exercise intensities may vary depending on the purpose of the intervention. For example, it has been suggested that improving cognitive performance may require high-intensity, interval training but preserving cognitive function in an aging brain may require a lower intensity, more continuous protocol ${ }^{74)}$. Exercise type may also be an important factor. Although most of the current literature has focused on $\mathrm{AE}$, other forms of exercise such as yoga ${ }^{75)}$ or weight training76) may also be beneficial in promoting brain health and cognition. Given the growing interest in exercise as a therapeutic intervention, it is surprising that very few studies have attempted a systematic evaluation for the most effective approach in psychiatric populations ${ }^{77-80)}$. It is important that future research is concentrated on establishing the merits of different forms of exercise and on detailed elucidation of the dose-response relationship between the intensity and length of $\mathrm{AE}$ intervention and therapeutic outcomes in different psychiatric populations.

\section{CONCLUSION}

There is, currently, a particular need to develop effective strategies that alleviate cognitive dysfunction. Targeting deficits in the neuroplasticity of areas crucial to cognition, such as the hippocampus, is a promising approach to remediating cognitive dysfunction. AE interventions represent an effective method for promoting hippocampal neuroplasticity and 
function, which encompasses few risks and several additional benefits for the patient. Future research should be aimed to establish standardized methodologies for investigating $\mathrm{AE}$ and to determine the most effective method for maximizing therapeutic outcomes with $\mathrm{AE}$ intervention. Improving our understanding of the role of lifestyle factors, such as exercise, in maintaining and promoting brain function could have major impact on the formulation of treatment and preventive strategies for psychiatric and neurological disorders. Research demonstrating the potential of $\mathrm{AE}$ in promoting hippocampal structural and functional integrity is growing at an impressive rate as more and more work is translated from animal models to humans.

\section{REFERENCES}

1) Van Cauwenberghe C, Van Broeckhoven $C$, Sleegers K: The genetic landscape of Alzheimer disease: clinical implications and perspectives. Genet Med. 18(5): 421-430, 2015.

2) Jedrziewski MK, Ewbank DC, Wang H, et al.: The impact of exercise, cognitive activities, and socialization on cognitive function: results from the national long-term care survey. Am J Alzheimers Dis Other Demen. 29(4): 372-378, 2014.

3) Okonkwo OC, Schultz SA, Oh JM, et al.: Physical activity attenuates age-related biomarker alterations in preclinical AD. Neurology. 83(19): 1753-1760, 2014.

4) Verghese J, Lipton RB, Katz MJ, et al.: Leisure activities and the risk of dementia in the elderly. N Engl J Med. 348(25): 2508-2516, 2003.

5) Sung YH: Effects of treadmill exercise on hippocampal neurogenesis in an MPTP /probenecid-induced Parkinson's disease mouse model. J Phys Ther Sci. 27(10): 3203-3206, 2015.

6) Nokia MS, Lensu S, Ahtiainen JP, et al.:
Physical exercise increases adult hippocampal neurogenesis inmale rats provided it is aerobic and sustained. $\mathrm{J}$ Physiol. 594(7): 1855-1873, 2016.

7) Speisman RB, Kumar A, Rani A, et al.: Daily exercise improves memory, stimulates hippocampal neurogenesis and modulates immune and neuroimmune cytokines in aging rats. Brain Behav Immun. 28: 25-43, 2013.

8) Andrieu S, Coley N, Lovestone S, et al.: Prevention of sporadic Alzh,eimer's disease: lessons learned from clinical trials and future directions. Lancet Neurol. 14(9): 926-944, 2015.

9) Paillard T, Rolland Y, Barreto PS: Protective effects of physical exercise in Alzheimer's disease and Parkinson's disease: a narrative review. J Clin Neurol. 11(3): 212-219, 2015.

10) Marosi K, Mattson MC: BDNF mediates adaptive brain and body responses to energetic challenges. Trends Endocrinol Metab. 25(2): 89-98, 2014.

11) Bekinschtein P, Oomen CA, Saksida LM, et al.: Effects of environmental enrichment and voluntary exercise on neurogenesis, learning and memory, and pattern separation, BDNF as a critical variable? Semin Cell Dev Biol. 22(5): 536-542, 2011.

12) Mattson MP: Lifelong brain health is a lifelong challenge: from evolutionary principles to empirical evidence. Ageing Res Rev. 20: 37-45, 2015.

13) Schafer MJ, Alldred MJ, Lee SH, et al.: Reduction of $\beta$ - amyloid and $\gamma$-secretase by calorie restriction in female Tg2576 mice. Neurobiol Aging. 36(3): 1293-1302, 2015.

14) Fratiglioni L, Paillard-Borg S, Winblad B: An active and socially integrated lifestyle in late life might protect against dementia. Lancet Neurol. 3(6): 343-353, 2004.

15) Garc'ia-Casal JA, Loizeau A, Csipke E, et al.: Computer-based cognitive 
interventions for people living with dementia: a systematic literature review and meta-analysis. Aging Ment Health. 25: 1-14, 2016.

16) Kishi T, Sunagawa K: Exercise training plus calorie restriction causes synergistic protection against cognitive decline via up-regulation of BDNF in hippocampus of stroke-prone hypertensive rats. in Proceedings of the 34th Annual International Conference of the IEEE Engineering in Medicine and Biology Society (EMBS '12): 6764-6767, 2012.

17) Kida Y, Goligorsky MS: Sirtuins, cell senescence, and vascular aging. Can J Cardiol. 32(5): 634-641, 2016.

18) Amigo I, Kowaltowski AJ: Dietary restriction in cerebral bioenergetics and redox state. Redox Biology. 2(1): 296-304, 2014.

19) Dhurandhar EJ, Allison DB, Groen T, et al: Hunger in the absence of caloric restriction improves cognition and attenuates alzheimer's disease pathology in a mouse model. PLoS ONE. 8(4): e60437, 2013.

20) Mushtaq R, Shoib S, Shah T, et al.: Relationship between loneliness, psychiatric disorders and physical health? A review on the psychological aspects of loneliness. J Clin and Diag Res. 8(9): 1-4, 2014.

21) Voss MW, Heo S, Prakash RS, et al.: The influence of aerobic fitness on cerebral white matter integrity and cognitive function in older adults: results of a one-year exercise intervention. Hum Brain Mapp. 2985: 2972-2985, 2013.

22) Sibley BA., Etnier JL: The relationship between physical activity and cognition in children: a meta-analysis. Pediatr Exerc Sci. 15: 243-256, 2003.

23) Tomporowski PD, Davis CL, Miller PH, et al.: Exercise and children's intelligence, cognition, and academic achievement.
Educ Psychol Rev. 20: 111-131, 2008.

24) Tomporowski PD, McCullick B, Pendleton DM, et al.: Exercise and children's cognition: the role of exercise characteristicsanda place for metacognition. J Sport Health Sci. 4: 47-55, 2014.

25) Yaffe K, Barnes D, Nevitt M, et al.: Aprospective study of physical activity and cognitive declinein elderly women. Arch Intern Med. 161: 1703, 2001.

26) Barnes DE, Yaffe K, Satariano WA, et al.: A longitudinal study of cardio respiratory fitness and cognitive function in healthy older adults. Am Geriatr Soc. 51: 459-465, 2003.

27) Middleton LE, Mitnitski A, Fallah N, et al. : Changes in cognition and mortality in relation to exercise in late life: a population based study. PLoSONE 3: e3124, 2003.

28) Wendell CR, Gunsta J, Waldstein SR: Cardiorespiratory fitness and accelerated cognitive decline with aging. J Gerontol A Biol Sci Med Sci. 69: 455-462, 2014.

29) Hamer M, Chida Y: Physical activity and risk of neurodegenerative disease: a systematic review of prospective evidence. Psychol Med. 39: 3-11, 2009.

30) Kramer AF, Erickson KI, Colcombe SJ: Exercise, cognition, and the aging brain. J. Appl Physiol. 101: 1237-1242, 2006.

31) Etnier JL, Salazar W, Landers DM, et al.: The influence of physical fitness and exercise upon cognitive functioning: ameta-analysis. J Sport Exerc Psychol. 19: 249-277, 1997.

32) Smith PJ, Blumenthal JA, Hoffman BM, et al.: Aerobic exercise and neurocognitive performance: a meta-analytic review of randomized controlled trials. Psychosom Med. 72: 239-252, 2010.

33) Chang YK, Labban JD, Gapin JI, et al.: The effects of acute exercise on cognitive performance: a meta-analysis. Brain Res. 
1453: 87-101, 2012.

34) Roig M, Nordbrandt S, Geertsen S, et al.: The effects of cardiovascular exercise on human memory: a review with meta-analysis. Neurosci Biobehav Rev. 37: 1645-1666, 2013.

35) Verburgh L, Konigs M, Scherder E, et al.: Physical exercise and executive function sinpreadolescent children, adolescents and young adults: a meta-analysis. $\mathrm{Br} \mathrm{J}$ Sports Med. 48: 973-979, 2013.

36) Colcombe SJ, Erickson KI, Raz N, et al. : Aerobic fitness reduces brain tissue loss in aging humans. J Gerontol Ser A Biol Sci Med Sci. 58: M176-M180, 2003.

37) Angevaren M, Aufdemkampe G, Verhaar HJ, et al: Physical activity and enhanced fitness to improve cognitive function in older people without known cognitive impairment. Cochrane Database Syst Rev. 16: CD005381, 2008.

38) van Uffelen J. Chin A, Paw MJM, et al.: The effects of exercise on cognition in older adults with and without cognitive decline: a systematic review. Clin J Sport Med. 18: 486-500, 2008.

39) Heyn P, Abreu BC, Ottenbacher KJ.: The effects of exercise training on elderly persons with cognitive impairment and dementia: a metaanalysis. Arch Phys Med Rehabil. 85: 1694-1704, 2004.

40) Gates N, Fiatarone Singh MA, Sachdev PS, et al: The effect of exercise training on cognitive function in older adults with mild cognitive impairment: a meta-analysis of randomized controlled trials. Am J Geriatr Psychiatry. 21: 1086-1097, 2013.

41) Etnier JL, Nowell PM, Landers DM, et al: A meta-regression to examine the relationship between aerobic fitness and cognitive performance. Brain Res Rev. 52: 119-130, 2006.

42) Snowden M, Steinman L, Mochan K et al.: Effect of exercise on cognitive performance in community dwelling older adults: review of intervention trials and recommendations for public health practice and research. J Am Geriatr Soc. 59: 704-716, 2011.

43) Young J, Angevaren M, Rusted J et al.: Aerobic exercise to improve cognitive function in older people without known cognitive impairment (Review). Cochrane Database Syst Rev. 22: CD005381, 2015.

44) Angevaren M, Aufdemkampe G, Verhaar HJ, et al.: Physical activity and enhanced fitness to improve cognitive function in older people without known cognitive impairment. Cochrane Database Syst Rev. 16: CD005381, 2008.

45) Colcombe S, Kramer AF: Fitness effects on the cognitive function of older adults: ameta-analyticstudy. Psychol Sci. 14: 125-130, 2003.

46) Burgess N, Maguire EA, O'Keefe J: The human hippocampus and spatial and episodic memory. Neuron 35: 625-641, 2002.

47) Bird CM, Burgess N: The hippocampus and memory: insights from spatial processing. Nat Rev Neurosci. 9: 182-194, 2008.

48) Tulving E.: What is episodic memory? Curr Perspect Psychol Sci. 2: 67-70,1993.

49) Yassa MA, Star CEL.: Pattern separation in the hippocampus. TrendsNeurosci. 34: 515-525, 2011.

50) Oomen CA, Bekinschtein P, Kent BA, et al.: Adult hippocampal neurogenesis and its role in cognition. Wiley Interdiscipl. Rev Cogn Sci. 5: 573-587, 2014.

51) Oomen CA, Hvoslef-Eide M, Heath CJ et al.: The touchscreen operant platform for testing working memory and pattern separation in rats and mice. Nat Protoc. 8: 2006-2021, 2013.

52) Clayton NS, Griffiths PD, Emery NJ, et al.: Elements of episodic-like memory in animals. Philos Trans R Soc Lond B Biol 
Sci. 356: 1483-1491, 2001.

53) Eichenbaum H, Fortin NJ, Ergorul C, et al: Episodic recollection in animals: "if it walks like a duck and quacks like a duck ....” Learn Motiv. 36: 190-207, 2005.

54) Templer VL, Hampton RR: Episodic memory in nonhuman animals. Curr Biol. 23: R801-R806, 2013.

55) Richards M, Hardy R, Wadsworth MEJ: Does active leisure protect cognition? Evidence from a national birth cohort. Soc Sci Med. 56: 785-792, 2003.

56) Stewart R, Prince M, Mann A: Age, vascular risk, and cognitive decline in an older, British, African-Caribbean population. J Am Geriatr Soc. 51: 1547-1553, 2003.

57) Sabia S, Nabi H, Kivimaki M, et al.: Health behaviors from early to late midlife as predictors of cognitive function: the Whitehall II study. Am J Epidemiol. 170: 428-437, 2009.

58) Flöel A, Ruscheweyh R, Krüger K, et al.: Physical activity and memory functions: are neurotrophins and cerebral gray matter volume the missing link? Neuroimage. 49: 2756-2763, 2010.

59) Ruscheweyh R, Willemer C, Krüger K, et al.: Physical activity and memory functions: an interventional study. Neurobiol Aging 32: 1304-1319, 2011.

60) Erickson KI, Kramer AF: Aerobic exercise effects on cognitive and neural plasticity in older adults. Br J Sports Med. 43: 22-24, 2009.

61) Erickson KI, Raji CA, Lopez OL, et al. Physical activity predicts gray matter volume in late adulthood: the cardiovascular health study. Neurology 75: 1415-1422, 2010.

62) Erickson KI, Voss M., Prakash RS, et al.: Exercise training increases size of hippocampus and improves memory. Proc Natl Acad Sci U.S.A. 108: 3017-3022, 2011.
63) Déry N, Pilgrim M, Gibala M, et al.: Adult hippocampal neurogenesis reduces memory interference in humans: opposing effects of aerobic exercise and depression. Front. Neurosci. 7: 66, 2013.

64) Chaddock L, Erickson KI, Prakash RS, et al.: A neuroimaging investigation of the association between aerobic fitness, hippocampal volume, and memory performance in preadolescent children. Brain Res. 1358: 172-183, 2010.

65) Chaddock L, Pontifex MB, Hillman CH: A review of the relation of aerobic fitness and physical activity to brain structure and function in children. J. Int. Neuropsychol. Soc. 17: 975-985, 2011.

66) Monti, JM, Hillman, CH, Cohen, NJ: Aerobic fitness enhances relational memory in preadolescent children: the FITKids randomized control trial. Hippocampus. 22: 1876-1882, 2012.

67) Stroth S, Hille K, Spitzer M, et al.: Aerobic endurance exercise benefits memory and affect in youngadults. Neuropsychol.Rehabil. 19: 223-243, 2009.

68) Herting MM, Nagel BJ: Aerobic fitness relates to learning on a virtual Morris Water Task and hippocampal volume in adolescents. Behav BrainRes. 233: 517-525. 2012.

69) Bavelier D, Neville HJ: Cross-modal plasticity: where andhow? Nat Rev Neurosci. 3: 443-452, 2002.

70) Bartsch T, Wuff P: The hippocampus in aging and disease: from plasticity to vulnerability. Neuroscience. 309: 1-16, 2015.

71) Singh NA, Stavrinos TM, Scarbek Y, et al.: A randomized controlled trial of high versus low intensity weight training versus general practitioner care for clinical depression in older adults. J. Gerontol. Ser A Biol Sci Med Sci. 60: 768-776, 2005.

72) Dunn AL, Trivedi MH, Kampert JB, et al.: 
Exercise treatment for depression: efficacy and dose response. Am J Prev Med. 28: 1-8, 2005.

73) Stanton R, Happell B: A systematic review of the aerobic exercise program variables for people with schizophrenia. Curr Sports Med Rep. 13: 260-266, 2014.

74) Duzel E, vanPraag H, Sendtner M: Can physical exercise in old age improve memory and hippocampal function? Brain. 139: 662-673, 2016.

75) Lin J, Chan SK, Lee EH, et al.: Aerobic exercise and yoga improve neurocognitive function in women with earlypsychosis. NpjSchizophr. 1: 15047, 2015.

76) Suo C, Singh MF, Gates N, et al.: Therapeutically relevant structural and functional mechanisms triggered by physicalandcognitiveexercise. Mol Psychiatry, 2016.

77) Perraton LG, Kumar S, Machotka Z: Exercise parameters in the treatment of clinical depression: a systematic review of randomized controlled trials. J Eval Clin Pract. 16: 597-604, 2010.

78) Stanton R, Happell B: A systematic review of the aerobic exercise program variables for people with schizophrenia. Curr Sports Med Rep. 13: 260-266, 2014.

79) Stanton R, Reaburn P: Exercise and the treatment of depression: a review of the exercise program variables. J Sci Med Sport. 17: 177-182, 2014.

80) Kimhy D, Lauriola V, Bartels MN, et al.: Aerobic exercise for cognitive deficits in schizophrenia the impact of frequency, duration, and fidelity with target training intensity. Schizophr Res. 172: 213-215, 2016. 